\title{
NUTRICIÓN
}

\section{Hábitos en preparación y consumo de productos hortícolas, sus aportes al equilibrio alimenticio. Familias Programa Arovia. Limpio, Paraguay, 2017}

María Irma Betzel', Pamela Raquel Salcedo', Vicenta Cáceres, Yenifer Daiana Martínez ${ }^{1}$, Diana María Isabel Rojas ${ }^{1}$, Mirian Susana Vera ${ }^{1}$, Kristel Lorena Villalba', María Paz Miranda¹, Jazmín Romero

\section{Resumen}

Introducción: Conforme a los resultados de la Encuesta Permanente de Hogares 2016, la población paraguaya considerada en situación de pobreza representa 28,86\% del total de habitantes del país, esto significa que alrededor de 1 millón 900.000 personas residen en hogares cuyos ingresos per cápita son inferiores al costo de una canasta básica de consumo, estimado para dicho año. La mayoría afecta a pobladores de área rural. El Programa Arovia Paraguay, presentado en el año 2014, ha sido instaurado por la Secretaría Nacional de la Juventud, la Secretaría de Acción Social, la Secretaría Técnica de Planificación y la Secretaría Nacional de Cultura; dentro de un Convenio para instalar al voluntariado en la cultura juvenil ciudadana y tiene como objetivo articular y coordinas las fuerzas de voluntariado, servicio cívico social y cultural en la juventud en torno a la lucha contra la pobreza y la desigualdad social, con un enfoque territorial, interinstitucional, sistémico y participativo. Esto se halla enmarcado en el Art. 56 de la Constitución Nacional, que promueve la participación activa de la juventud en el desarrollo político, económico, social y cultural del país. Es un programa que tiene prevista su continuación para afianzar la implementación de las políticas sociales, y especialmente la reducción de la pobreza, causa nacional que debe involucrar a todos los paraguayos y a los jóvenes en particular, como está previsto en el Art. 129, de la Constitución Nacional. Integrando este Programa, algunas familias de escasos recursos en diferentes lugares del país, realizan huertas que les permite obtener hortalizas y verduras para complementar sus necesidades nutricionales. Estudiantes de la carrera de Nutrición (UNIBE), a partir del mes de mayo del año 2017, en ejercicio de sus responsabilidades sociales, se unen a este programa visitando las poblaciones vulnerables, llevando a cabo trabajos de extensión universitaria y de diagnóstico para abordar una investigación en base a la problemática y afianzar el proceso de empoderamiento de acciones capaz de transformar la realidad de sus habitantes. Según la información brindada por la Secretaría Técnica de Planificación del Desarrollo Económico y Social (STP), desde el 2015, más de 45 voluntarios profesionales pasaron por el programa, los mismos

\footnotetext{
1. Facultad de Ciencias de la Salud, Universidad Iberoamericana, Paraguay.

E-mail: sbetzel_letras@yahoo.com.ar

DOI: 10.26885/rcei.foro.2017.110
} 


\section{Hábitos en preparación y consumo de productos hortícolas. Betzel et al.}

vivieron y acompañaron a más de 25.000 personas en comunidades vulnerables de cinco departamentos del país (14 distritos y 30 comunidades) acercando proyectos locales en base a las necesidades expresadas por los pobladores para reducir la pobreza y lograr mayor crecimiento económico. El Asentamiento Nuevo Amanecer, ubicado en Limpio, es el escogido para este trabajo. En este lugar, alrededor de dieciocho familias se han integrado al Programa Arovia desde el año 2015 y están, actualmente, aprovechando sus propios productos hortícolas.

Objetivos: La investigación tuvo como objetivo general analizar hábitos de preparación y consumo en productos hortícolas y sus aportes al equilibrio alimenticio en las familias incluidas en el Programa Arovia, en Limpio, 2017. Los objetivos específicos son: describir prácticas vinculadas a la preparación de alimentos, indicar hábitos en el consumo de hortalizas y verduras; y determinar la contribución de las huertas a los criterios nutricionales recomendados.

Material y Método: Se ha iniciado la aplicación de instrumentos de recolección de datos en el mes septiembre en el asentamiento "Nuevo Amanecer" de Limpio, aplicándose entrevistas semiestructuradas y encuestas con preguntas cerradas o dicotómicas y otras abiertas. También se elabora un registro anecdótico y fotográfico. Algunas pruebas piloto fueron aplicadas con anterioridad en visitas previas, en base a las mismas, se realizaron ajustes en los instrumentos elaborados. Resultados: Se espera que los resultados revelen información acerca del provecho que estas familias, obtienen de los productos de su huerta y detectar falencias que permitan optimizar el programa en esta comunidad $y$, por ende, en otras comunidades, ya que Arovia, según lo previsto, continuará extendiéndose a otras poblaciones y por ser de una conformación relativamente reciente, los datos que se recaben servirán de apoyo para importantes diagnósticos. Hasta el momento, se está cumpliendo el cronograma establecido, se han realizado incursiones en la zona, con la elaboración de planos y registros informatizados, para tener un desplazamiento apropiado en el lugar. Los resultados de las pruebas pilotos han permitido hacer ajustes a los instrumentos. Las personas encuestadas han demostrado buena disposición para aportar los datos requeridos y también para manifestar inquietudes en cuestiones que pueden ser objeto de otros estudios en el futuro, lográndose un avance satisfactorio de la investigación. Se ha iniciado, además, el registro fotográfico.

Palabras clave: Programa Arovia, productos hortícolas, equilibrio nutricional, hábitos.

\section{Referencias}

Ghiglioni. M., Itzik. A., Pícolo. A. (2008). Todo sobre la vida sana y natural. Montevideo: Editorial Latinbooks Internacional.

López, L., Suárez, M. (2017). Fundamentos de nutrición normal. Buenos Aires: El Ateneo. 
Rev. cient. estud. investing. VI Foro de Investigadores; diciembre 2017

Ministerio de Salud Pública y Bienestar Social. Dirección General de Programas de Salud. INAN. (2015). Guías Alimentarias del Paraguay. Comité Técnico Nacional de las Guías Alimentarias; Asunción: MSPyBS. 